\title{
Transforming Organizational Change through Collaborative Digital Storytelling
}

\author{
William Tate Brendel \\ University of St. Thomas \\ Chientzu Candace Chou \\ University of St. Thomas
}

\begin{abstract}
Planned or unplanned, organizational change can be an arduous, confusing, and lonely endeavor, unless individuals are afforded a platform for makin $g$ sense of their unique relationship with change. Through the lens of Transformative Learning Theory, which views adult learning as a process of meaning-making, this article demonstrates how contextual facets of digital (online) storytelling may assist individuals, departments, and the organization as-a-whole. Particular, in sharing their storied relationships with change, reflecting upon habits of mind, and coming to consensus on a creative and cohesive path forward.
\end{abstract}

Keywords: digital storytelling, collaborative learning, transformative learning, organizational change

\section{Introduction}

The aim of this article is to demonstrate why and how Collaborative Digital Storytelling (CDS) provides an atmosphere for authentic, reflective, and innovative discourse around three critical relationships that employees have with organizational change including: (1) an individual's story about change in relationship with their department's collective story, (2) a department's collective story about the change in relationship with its organization's collective story, and (3) an organization's collective story of change as well as its connections and implications for its individuals and departments. Organizations in this article denote social units that are formed for specific purposes including education, government, non-profit, and business institutions. To demonstrate use of digital storytelling, this article first reviews literature that links storytelling with the sense of self, organizational identity, strategy, and organizational culture. Second, through the lens of Transformative Learning Theory(Fisher-Yoshida, Geller, \& Schapiro, 2009; Mezirow et. al, 2000; Taylor \& Cranton, 2012), this article demonstrates how stories 
can serve as gateways for exploration and transformation when coming to takenfor-granted assumptions, habits of mind, and automatic behaviors in the context of organizational change. Third, this article demonstrates a straightforward method for identifying and deconstructing aspects of a story that are universal and highly influential. Specific components of a story that deserve careful reflection and dialogue in the service of transformation and discovering common ground is given. Fourth, adiscussion is given of how specific characteristics of CDS, when compared with face-to-face storytelling, could provide a more trusting, comfortable, and creative space for engaging in the transformative processes of sharing, comparing, exploring, rethinking, and aligning stories. This article concludes with a detailed description of the CDS process and an example of how this may be tailored to accommodate a variety of organizational change settings. In order to assist the reader, defining two key terms utilized throughout this article up front is important. They include:

- Collaborative Digital Storytelling (CDS): A collaborative online storyboarding methodology that invites employees from all corners of an organization to share, reflect upon, map-out, transform, and restory their authentic relationships with planned or unplanned organizational change.

- Change-Story: Any story produced by an individual, department, or organization, which expresses an interpretation of how and why the organization is changing including a genuine relationship with change, and serves as an object for critical reflection and reflective dialogue that may result in a revised change-story.

\section{Literature Review}

\subsection{Storytelling \& Organizing}

The concepts of storytelling and meaningmaking are inseparable as the word 'meaning' derived from the Old English term maenen, connotes one's story (Barnhart, 1995). Stories have served people since the early ages in which they began to organize as a primary means for social bonding (Butler \& Bentley, 1997). The relationship between stories and the way people make sense of the world is well-studied (Birren, Kenyon, Ruth, Schroots, \& Svensson, 1996; Markus \& Nurius, 1986; Park \& Blumberg, 2002; Strong \& Psych, 2005; Williams \& Hayler, 2016; Wilson \& Hayes, 2000). Organizations themselves are said to be storytelling systems, wherein stories are "the preferred sense making currency of human relationships with internal and external stakeholders" (Boje, 1991, p. 106). Stories are known to improve organizational effectiveness (Oliver \& Snowden, 2005; Snowden, 2004), strategic planning (Horst \&Järventie-Thesleff, 2016; Shaw et al., 1998), and leadership dialogue (Barry \&Elmes, 1997). Pedagogically speaking, stories are "... one of the fundamental sense-making operations of the mind" (Lodge, 1990, p. 141),yet formalizing sense-making and organizing through story in organizations could not be more complex.

\subsubsection{Stories and Sense of Self.}

Our stories often adhere to emotionally charged events that often tie interpretation of the present situation to the past. Storied depictions of these more memorable experiences can inform, inspire, and even haunt people over the course of a professional lifetime. Therefore, stories are known to have a strong valence with people's very sense of self (Markus \& Nurius, 1986)including how they identify with others in the organization (Ashforth, Schinoff, \& Rogers, 2016) and their unique 'felt experience' in the organization (Watson 1995; Weik, 1995). People are, as 
Birren et al. (1996) put it, "co-authors of the 'stories we are' by virtue of our capacity for creating and discovering meaning" (p. 5). As a result, autobiographical inquiry has emerged as a form of organizational research (LuciusHoene\&Deppermann, 2000) that greatly informs the process of CDS described later. Also possible is to hold stories apart from people in order to control, study, and reshape the meaning of their lives including the change inevitably encountered. In other words, stories are ripe for rethinking, revising, and representing identity in relationship to change.

\subsubsection{Stories and Organizational Identity.}

The processes of revisiting and revising stories carry profound implications in organizational settings, particularly in the context of strategic change initiatives that call for reconsidering relationship with the organization on both an individual and collective scale (Dunford \& Jones, 2000). As a collaborative effort, re-storying does not merely provide amethod of consensus building. It moves beyond comparing descriptions of shared experiences to engaginging critical dialogue around the underlying premises for change that is often overlooked, which are embedded - if only to be 'found' - in the story itself. A potential out growth of this reflective process is that it may resolve otherwise unresolved conflicts and in some cases transform the story, including an employee's sense of identity within the organization, so radically that it no longer resembles the original form or function.

Organizational change and the anxiety it produces have become a hallmark of modern life. Leaders may be said to have not only a strategic obligation, but also a moral obligation to explore new platforms that help a greater majority of employees revisit change and the anxieties it provokes. Stories provide a helpful space for sense making around sentient organizational experience including the identity and roles people play in organizational life. This article elaborates on these positions by discussing how the storied relationship associates with change such as (a) how people make sense of change through the stories they tell others, (b) repeating subconsciously to themselves, and (c) upholding unmentioned organizational expectations, strategic orientations, and relationships with organizational culture.

\subsection{Stories, Strategy, and Culture}

Through the lens of Transformative Learning Theory (Mezirow et al, 2000; Taylor \&Cranton, 2012) discussed later in this article, it is possible to see how mindfully storying, reflecting, and re-storying can lead to adaptive, real-time personal change in alignment with strategic organizational change. When coming to strategy and organizational culture, stories afford managers the ability to see and discuss with greater clarity, and the patterns of themes that arise in current organizational interactions as well as future expectations for organizational success (Dunford\& Jones, 2000).

Change stories can be produced by individuals, groups, or units for the expressed purpose of strategic alignment. For instance, employees can work together to create a shared vision in an online community. Employees can also use stories to align with an organizational vision that is already in motion. Stories may also be used as a dialogic form of exploration concerning the way employees draw from their unique experiences to individually making sense of the meaning and values in vision statements.

As meaning-making is essentially a function of continuously interpreting events, it can be said that the stories regularly shared with others and repeated to echo some of 
people's deepest assumptions helps in this process. Understanding organizational culture involves "...examining the shared assumptions in the organization or group one is dealing with and comparing them to one's own..." (Schein, 2004, p. 5). Stories not only reflect personal assumptions, but also illustrate broader habits of mind that may be shared by two or more colleagues. A habit of mind is defined in Transformative Learning Theory as, "a set of assumptions - broad, generalized, orienting predispositions that act as a filter for interpreting the meaning of experience" (Mezirow, 2000, p. 17). Storytelling provides ample room for reflection around an organization's shared assumptions; particularly those that are unhelpful, impede smooth functioning, and interrupt the sustained competitive advantage of an innovation.

The reader might visualize individual stories like waves that move atop the undercurrent of organizational culture. Sometimes the stories shared, or privately kept in mind, move against these deeper currents. They may also clash aggressively against the stories of others. This is one of the reasons why dealing with change can feel like a harsh, confusing, and lonely process. In contrast, when an individual's story aligns with the greater cultural current of the organization, they may be unintentionally supporting elements of the status quo that ultimately hurt the organization. People's inability to mindfully surface and reflect upon stories may be one of the chief reasons why seemingly straightforward change efforts become so tumultuous and unpredictable.

\subsection{Reflecting upon Change-Stories}

Storytelling has been noted as an emancipatory process that helps individuals "explain or express" in order to "analyze or understand" (Reason \& Hawkins, 1998, p. 79).
Important however, is to have basic insight around how meaning is formed through stories before it can be transformed. The process of meaning-making has been studied from a variety of perspectives (Lazarus \& Folkman, 1984). This article adheres to the central contours of Park and Folkman's (1997) model, supported by a number of interdisciplinary authors, where meaning-making involves making sense of and finding meaning in an event (McIntosh et al., 1993; Silver, Boon \& Stones, 1983 as referenced by Park \& Folkman, 1997).

After a heated discussion in a team setting, people can invite one's storied account without biasing their response by simply asking "What just happened?" Colleagues who sat through the very same meeting can have vastly different stories of what happened. When shared, colleagues can begin analyzing divergent interpretations of a sequence of events, known as "surface patterns," through the lens of a process theory (Pentland,1999, p. 711). In this way, stories can elicit internal points of view regarding who plays the protagonist versus the antagonist, when the conflict initially arose, who stoked the flames, and what important opinions went unspoken. In this way the narrative assign to the event represents a unique "theory as narrative" (DiMaggio, 1995 as cited in Pentland, 1999), through which "... an explanation is a story that describes the process, or sequence of events, that connects cause and effect... In this view, good stories are central to building better theory" (Pentland, 1999, p. 711).

Unless a team or organization facilitates dialogue around storied accounts or theories, the meaning of any event may be viewed collectively as a rather unfortunate clash of perspectives; too messy to be worth the effort of critical reflection during a busy workday. Only through dialogue and critical reflection upon both content and process, where multiple 
assumptions are entertained, can the collective co-construct a common story.

Not so much are the stories themselves important, but the ability to recognize hidden assumptions and deconstruct how they influence behaviors that matters when attempting to transform people's sense of self, organizational identity, strategy, and culture. With the help of others, particularly through reflective discourse (e.g., reflecting on assumptions with others), individuals may be better equipped to recognize and address, perhaps for the very first time, unhelpful habits of mind; whether unique to the individual or shared. Mindfully surfacing and addressing stories involves a great deal of cognitive and emotional effort, but it can also make behavioral change less arduous. When reflective discourse extends beyond individuals and teams this can permeate the collective organization, transforming the deepest currents effecting organizational change.

\subsection{Transforming Change-Stories}

When it comes to reflecting upon and transforming sense of self, organizational identity, and alignment with strategy and culture, it is necessary to dig deep into assumption with the help of a theoretical lens. Transformative Learning Theory (Mezirow, 2000) offers a helpful framework for identifying specific habits of mind that reinforce personal conceptions around organizational change. This theory is also helpful because it honors the many singularities associated with storied meaning. Inviting unique perspectives from employees can contribute to a felt sense of ownership around a revised story, and fortunately, this theory validates this type of intimacy. Transformative Learning Theory approaches adult learning specifically as a matter of meaning-making, where one can assume that there are multiple ways of understanding or gaining insight into a problem (Mezirow, 2000). When faced with a disorienting dilemma, such as the team conflict described above, Merriam and Caffarella (1999, p. 321) describe the basic process of transformative learning in three phases: critical reflection, reflective discourse, and action. In collaborative storytelling, the stories become the object of reflection across this threefold process. As it is collaborative, this process also scaffolds reflection across three levels of the organization including: individuals, departments, and the organization as a whole.

Two types of transformation can occur through this process: objective and subjective reframing of change-stories. Mezirow suggests that through critical reflection and reflective dialogue people may engage in: (1) objective reframing, where they transform description of the storied problem and understanding of the problem-solving process; and (2) subjective reframing, a selfreflective process in which habits of mind are transformed when people become aware of the underlying premise of a problem (Mezirow, 2000 , p. 23). Objective reframing entails a new way of understanding and completing tasks associated with change because it speaks directly to strategic behaviors (mindful or automatic) as well as taken for granted orientations to problem solving. Subjective reframing in this context may entail a fundamentally different way of seeing the organizational identity in relationship to change. It speaks directly to the roles and relationships with others. For example, people might not view themselves as leaders if not given formal authority by the organization. Yet, they can change this by exploring the definition of leadership and finding opportunities in their own story for leading. 


\subsection{Universal Components of Change Stories}

As mentioned in the introduction, stories that tend to be remembered are the ones that contain the greatest emotional charge. The charge itself is often a product of struggling to reach a desired state followed by success or failure. Robert McKee (2003) proposed four elements of compelling stories that may be incorporated as part of leadership strategy in the organizational setting, which include the storied: struggle, values, beats, and climax.McKee (2003) refers to a 'struggle' as the meaningful change experienced by the protagonist (insert: you, your department, and your organization), and is expressed through 'values,' which are universal qualities of human experience that shift from positive to negative from one moment to the next. 'Values' are the places where people connect and relate to others, regardless of context. 'Beats' are the exchanges in action and reaction, also from one moment to the next. Lastly, 'climax' refers to the point in which the string of events brings about an absolute change (McKee, 2003). In transformative collaborative storytelling, climax may also be understood as the transformation in the story that results from the individual or group traversing through all the previous elements of a story. It can also refer to the potential for transformation as explored by the employees, departments, and organization as a whole. When reflecting upon stories, employees can ultimately decide which elements of the story might ultimately transform, what the transformation looks like, how this is measured, and what revised roles and tasks are required to make the transformation possible.

Within the struggle, values, beats, and climax of a change-story, there are numerous ways to design questions to effectively identify and facilitate reflection upon subjective habit(s) of mind. People might start with metaphors that symbolize organizational culture, because culture tends to direct them "... to phenomena that are below the surface, that are powerful in their impact but invisible and to a considerable degree unconscious" (Schein, 2004, p. 8). A particularly strong area of language upholding organizational culture, and some have even suggested could essentially manage, includes the metaphors people invoke when speaking about change (Marshak, 1993). Examples of common change-story metaphors include: 'this ship is sinking,' 'this unit operates like a well-oiled machine,' 'this not in the DNA of our leaders,' 'this place is run like a sweat shop,' 'this is not Kansas anymore,' and 'this is your choice: either get on the bus or off the bus.' Asking questions about what lies beneath these metaphors allows peopleto reflect upon shared assumptions; particularly those that support problematic beliefs (Mezirow, 2000, p. 53). Together, employees can consciously question and reshape their shared interpretations of organizational change. Considering the malleable nature of change-stories, universal elements of story, types of transformation (objective and subjective), and the ability to hold stories apart from ourselves for critical reflection and reflective dialogue, can people begin mapping a strategy for facilitating storied transformations. Consider Table 1 below, in which a change agent might design specific questions to elicit fruitful areas for individual and collective reflection.

People can begin this reflective journey by simply describing events. When they elicit rich accounts from different vantage points, participants will begin to see assumptions that may or may not be true about the given story. Take for instance the change-story depicted in Table 2 below. 


\section{CollaborativeDigital Storytelling (CDS)}

\subsection{Components of CDS}

Just as important to map out 'what' people can reflect upon and how that reflection can take place to potentially transform understanding is developing an optimal platform and dialogic environment that supports both involvement and creativity. CDS contains four dichotomous characteristics that help make this possible including: connected space, flexible timing, creative process, and shared purpose (Figure 1).

1. Connected space: The processes of analysis described in the first half of this article can be conductedin either a private or public space for small groups or the organization at large. No matter how narrow or broad the window is for sharing, digital storytellers are connected through a virtual space where they may share narratives via text, audio, or video. With the advent of digital and social media tools, many have found new outlets in online communities to share their stories or voices under a common framework such as CDS. The framework must delineate the purpose, structures, and outcomes of the collaborative digital storytelling. For this purpose, the authors identified CDS as an online, collaborative, and asynchronous storyboarding methodology that invites employees from all corners of an organization to share, reflect upon, map-out, transform, and re-story their authentic relationships with planned or unplanned organizational change. Alexandar and Levine (2008) note that "stories now are open-ended, branching, hyperlinked, cross-media, participatory, exploratory, and unpredictable" (p. 40). A few tools are highlighted in the following section that makes this all possible in a straightforward fashion.

2. Time: Digital storytellers can participate at a flexible time that is convenient to them. CDS can be carried out over a certain period of time asynchronously (e.g., an elapsed time between two or more people) or synchronously when everyone is at the same digital space (not necessary physical space) at the same time. This feature is especially important in international organizations where teams are dispersed globally. The CDS process can also serve as a means for real-time brainstorming for virtual team meetings. CDS can be implemented asynchronously to allow time for reflection before sharing narratives. The key in facilitating CDS is selecting tools that can aggregate the stories in a meaningful display. Studies have shown that online participants can be more productive in contribution through asynchronous means (Hrastinski, 2008). Participants tend to generate more thoughtful utterances via asynchronous online discussion.

3. Creative process: The process of CDS invokes creativity in individuals when they are encouraged to express their opinions and be authentic with their comments. The process can also foster a sense of engagement and community where they belong to a shared space (LeeTiernan\&Grudin, 2001).

4. Purpose: Collaborative digital storytellers share their narratives under an identified common goal that is important to the growth of the organization. The process can start with individual expressions through the connected virtual space. The individual expressions then become the source of a collective wisdom that can lead to a shared vision to address organization missions.

Using tools such as blogs or YouTube for digital storytelling does not come without its concerns. With the dawn of Web 2.0 applications, large volumes of stories became unfathomable to the degree that it 
Table 1. Mapping storied transformations

\begin{tabular}{|c|c|c|c|c|c|c|}
\hline $\begin{array}{l}\text { Universal } \\
\text { Components } \\
\text { of Change } \\
\text { Stories }\end{array}$ & $\begin{array}{l}\text { Descriptive } \\
\text { Assumptions }\end{array}$ & $\begin{array}{l}\text { Prescriptive } \\
\text { Assumptions }\end{array}$ & $\begin{array}{l}\text { Objective } \\
\text { Elements }\end{array}$ & $\begin{array}{l}\text { Epistemic } \\
\text { Habits of } \\
\text { Mind }\end{array}$ & $\begin{array}{l}\text { Socio- } \\
\text { linguistic } \\
\text { Habits of } \\
\text { Mind }\end{array}$ & $\begin{array}{l}\text { Psychological } \\
\text { Habits of Mind }\end{array}$ \\
\hline $\begin{array}{l}\text { Values } \\
\text { Beats }\end{array}$ & $\begin{array}{l}\text { How did } \\
\text { the change } \\
\text { happen? }\end{array}$ & $\begin{array}{l}\text { Why did } \\
\text { the change } \\
\text { happen? }\end{array}$ & $\begin{array}{l}\text { Why } \\
\text { did } \\
\text { I choose } \\
\text { to take } \\
\text { specific } \\
\text { actions? }\end{array}$ & $\begin{array}{l}\text { What do I } \\
\text { privilege } \\
\text { as the } \\
\text { source of } \\
\text { knowledge } \\
\text { in this } \\
\text { scenario? }\end{array}$ & $\begin{array}{l}\text { What } \\
\text { metaphor } \\
\text { do I invoke } \\
\text { and what } \\
\text { does it } \\
\text { mean/ } \\
\text { express } \\
\text { in this } \\
\text { context? }\end{array}$ & $\begin{array}{l}\text { How and why } \\
\text { am I attached } \\
\text { to this change } \\
\text { story? }\end{array}$ \\
\hline
\end{tabular}

is impossible to derive themes or patterns from the information (Alexander \& Levine, 2008; Rossiter \& Garcia, 2010). Critics also are concerned at the overuse of digital effects may distract viewers from the narratives if the effects are not used purposefully (McClean, 2008). The authors emphasize the utilization of a web-based collaborative tool to manage the volume. A recommendation is the use of text-based tools because studies have shown

Table 2. Change story of Virgin Atlantic

Universal
Components Descriptive Assumptions
of Change
Stories

\begin{tabular}{ll}
\hline \multirow{3}{*}{ Struggle } & Richard Branson's business has always been a bit of a mystery. In fact, in 1992, \\
& a cash shortage forced Branson to unload one of his flagship businesses: Virgin \\
& Atlantic. \\
& Even in the face of this struggle, Branson was eager to get back up and try \\
Values & again. This time his focus turned towards breaking new ground, new records, \\
& and transforming the minds of his clients. \\
& Virgin decided to pay up to $\$ 21.5$ million for an exclusive license to the core \\
& design and technologies of spaceship technologies from SpaceShipOne. Even \\
& in the face of doubt, Branson continued by investing his money where his \\
Beats & values were, including $\$ 50$ million to build five passenger spaceships and \\
& another $\$ 50$ million to develop an operations unit. Finally, Branson released his \\
& ground-breaking service: a two hour flight beyond earth's atmosphere. \\
& Virgin Galactic was born, bringing space travel to an affordable level for the \\
Climax & 'every man.'
\end{tabular}


that online participants can be more productive in this mode (Hrastinski, 2008).

This article is primarily concerned with a collaborative process of transformative learning so linking the online components resembling a creative space is important (Hrastinski, 2008; LeeTiernan \& Grudin,
2001; Payloff \& Pratt, 1997; Pratt, 1996) including anonymity and both synchronous and asynchronous participation,with drivers of an authentic creative act. Online environments can provide something that too often in-person collaboration cannot: greater anonymity and asynchronous participation. These two ingredients may be just what are needed to

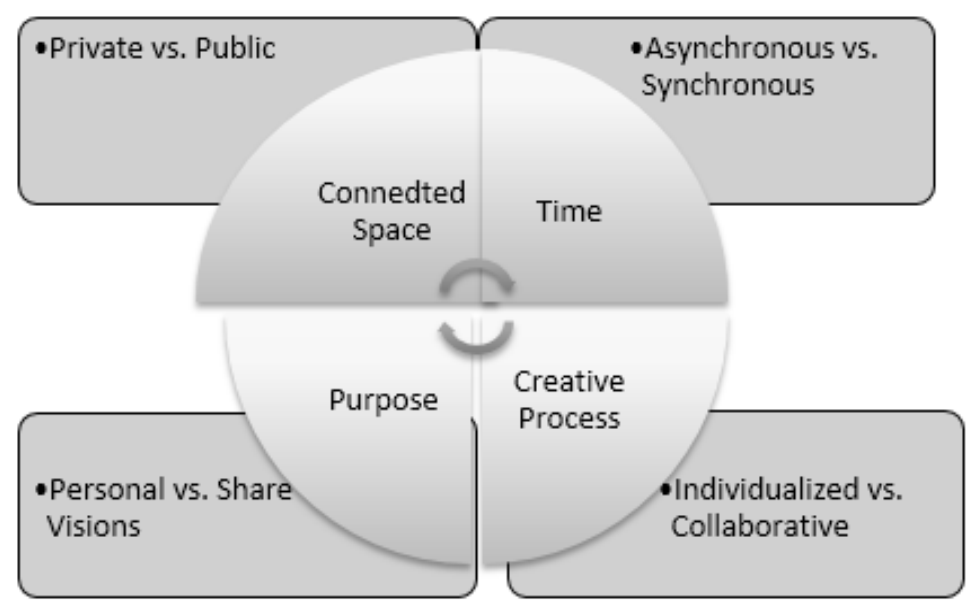

Figure 1. Components of Collaborative Digital Storytelling.

spark and stoke an employee's intensity of encounter with the creative act. It can also deepen a felt sense of engagement with one's self and others (Lee Tiernan \& Grudin, 2001). What might also be referred to as an intensity of duty to others through the fulfillment of authentic voice is essential, as Rollo May (1975) suggests, "If you do not express your own original ideas, if you do not listen to your own being, you will have betrayed yourself. Also, you will have betrayed your community in failing to make your contribution" (May, 1975, p. 12).
Anonymity, which is relatively easy to arrange in online collaborations, can serve to inoculate power differences and quell self-censorship. This is an opportunity to hide identity in service to a greater truth. Anonymity can serve to bring about both true 'self' and uncensored voice, which often are not revealed in-person for fear of retribution, whether that fear is rational or irrational. When working in-person people often do their best to resemble (in words and deeds) what is expected, even if it causes dissonance with internal values, assumptions, and expectations. 
Anonymity affords employees an opportunity to release this pressure through authentic narrative. As a result, anonymity affords a safe space for the personality to be revealed (p. 119-120, cited in Palloff \& Pratt, 2007, p. 29). One's level of authentic expression online may be so deep that if their name is later revealed, others might respond by saying 'that is not something I would ever expect you to say!'

As discussed above, asynchronous participation and anonymity are in many ways conducive to a greater intensity of encounter due to a sense of privacy (Pratt, 1996) and safety, where individuals may freely and fully release their inner voice. Creative encounter is the moment when people show up fully to a collaborative process, with an exhilarating sense of purpose and freedom in addressing the subject and its ability not just to survive, but to thrive in times of change (May, 1975). The use of story assembles these features in a unique, intimate, cohesive, and altogether meaningful fashion. Time and space also allow participants to create in a smooth and consistent flow, free from interruption or dislocation from 'self' (May, 1975).

\subsection{A Process for Collaborative Digital Storytelling}

CDS presents an exciting shift in traditional storytelling as it focuses on one person's narrative on a virtual space to a new genre that emphasizes a joint effort by multiple stakeholders in a common connected space. Traditional storytelling encourages individuals to share their life stories such as those stored on the Center for Digital Storytelling (http:// storycenter.org/stories/) or Educational Use of Digital Storytelling (http://digitalstorytelling. coe.uh.edu/). Digital storytelling has seen a wide application in education (Cordero et al., 2016; Phan, McNeil, \& Robin, 2016; Sarıca \& Usluel, 2016; Yang \& Wu, 2012).
Organization-based digital storytelling is emerging as well (Couldry, 2008; Hull \& Katz, 2006). Lambert (2013) suggested seven steps of digital storytelling: (1) owning your thought, (2) owning your emotion, (3) finding the moment, (4) seeing your story, (5) hearing you story, (6) assembling your story, and (7) sharing your story (p. 54-69). These steps provide an excellent framework to present one's own story in a meaningful way. In the author's proposed model, it goes one step further to invite the viewers to become active participants. Through continuous interaction and creative collaboration, every participant in an organization can own the story and contribute to shared visions. What is created and reflected upon can become the source of collective wisdom, which can lead to a shared vision to address organizational change (Pratt, 1996). Considering the elements of a story and its relationship with the organizational life, processes associated with transformative learning, and the relationship between collaborative space and the creative act, this section proposes a straightforward process to achieve this aim.

Step 1: Creating, Reflecting Upon, and Revising the Individual Story

At the individual level, using a digital storytelling platform, each member of the department is encouraged to develop their own stories around their relationships with a particular organizational change, by incorporating their personal struggles, interpretation of the changes at hand, and desired outcomes. Then, using specific storymapping software available online (examples provided below), individuals are encouraged to answer specific assumption-level questions that drill down to the points of view and habits of mind expressed in their story. After reflecting on these areas, individuals are then encouraged to re-imagine and re-story their 
relationships with change.

Step 2: Mapping, Reflecting Upon, and Revising the Departmental Story

Next, using this same software, members of a department are able to concurrently see their revised stories in relationship with those of other department members. This can be particularly fruitful to do so in an anonymous fashion. Department members are then asked to collaborate in critically exploring their individually transformed perspectives and arrive at consensus around a single departmental story that depicts a common understanding of change, shared values, goals, and a desired departmental relationship with change. Together the department writes a transformed story concerning the departmental level of change.

Step 3: Consolidating, Reflecting Upon, and Transforming the Organizational Story

Then, department leaders are encouraged to share their revised 'department level' stories with all other departments comprising the organization. Similar to step two, departmental leaders then collaborate to compare and contrast stories between departments that have also completed step two, in order to develop consensus around shared aspects of change at the organizational level. Together, departmental leaders write a transformed story concerning the organizational change.

Step 4: Exploring Relationships between the Individual and Organizational Story

Finally, all employees are encouraged to take a step back and consider the relationships between their revised story and the revised story of the organization as a whole. The aim of this final step is to provide employees with a better sense of how their transformed stories are indeed part of and aligned with a system level interpretation of change.

\subsection{Tools for CDS}

There have been a few tools developed to encourage processes like CDS. Some helpful tools include those originally designed for fiction writing such as StoryMash ${ }^{\mathrm{TM}}$ (http://storymash.com/) or Storify ${ }^{\mathrm{TM}}$ (http:// storify.com/). However, no tools have been developed specifically for organizational learning processes such as CDS. After fieldtesting a few tools, the following tools and examples do have potential for supporting the rich process associated with CDS. These tools include Coggle.ItTM (http://coggle. it), StormBoard (https://www.stormboard. com/), and Padlet (http://padlet.com). All of these tools allow collaboration with multiple participants. For instance, Coggle.It ${ }^{\text {TM }}$ presents visuals in the concept map format. Padlet $^{\mathrm{TM}}$ and Stormboard ${ }^{\mathrm{TM}}$ on the other hand, depict storieson a corkboard with sticky notes. Stormboard ${ }^{\mathrm{TM}}$ is particularly noteworthy, because it allows participants to vote in order to determine the relevancy of various ideas. Below is one example of the CDS process using Padlet ${ }^{\mathrm{TM}}$ that allows multiple users to co-author on the board from anywhere anytime (Figure 2).

\section{Conclusion}

As this process is relatively new, it certainly requires testing and further exploration in connection with a number of change contexts including as mergers, reorganization, and both small and large scale strategic realignment. Utilizing the CDS framework as it has been qualified and described throughout this article, further research studies would also do well to focus on the transformative effects of CDS; particularly how change-stories bring about a sense of resilience, playful innovation, 
and cohesion. Studies may also choose to examine the impact of CDS in contrast with face-to-face dialogue to better understand the effectiveness.

\section{Organization Visions}

Struggle
What are my main concerns
facing changes or
organization?

We're merging but T\&D was always an arm of OD! Why isn't our Mgr the head of the Center for Excellence?

Resistant to change, lack of OD skills, overlapping

functions

I'm afraid that they may find we have jobs overlapping, which could lead to people getting cut from positions

\section{Values}

What are important to

me facing the new

challenges

Need transparency,

competing interests

may creat barriers; $O D$

skills can complement

the gap in T\&D

We are upset because nobody from our department was consulted in the process of this merger.

T\&D has a limited view of the organization - they see everything as a training solution, but the OD folks know that you really need to take a systems view of the organization.
Beats

What are the critical changes that need to take place?

Need specific action plans; survey can collect input for further action

During the announcement we were too goal oriented and didn't focus enough on team building. We never got to meet people from the other department!
Climax

What do I hope to see accomplished?

Shared leadership and increased teamwork

I hope that we will be able to enter a partnership role together so that T\&D can see where their view of how to help the organization fits with our philosophy.

My additional hope is that we can combine our collective knowledge so that we can see a larger picture of the organization and draw correlations between different measures (i.e. needs assessments, employee satisfaction scores, etc...)

Figure 2. .Departmental Level Storied Relationships with the Organization (Created in Padlet ${ }^{\mathrm{TM}}$ ) 


\section{References}

Alexander, B., \& Levine, A. (2008). Web 2.0 storytelling: Emergence of a new genre. Educause Review, 43(6),40-56.

Ashforth, B. E., Schinoff, B. S., \& Rogers, K. M. (2016). "I Identify with Her,"“I Identify with Him": Unpacking the Dynamics of Personal Identification in Organizations. Academy of Management Review, 41(1), 28-60.

Barnhart, R. (1995). Barnhart concise dictionary of etymology. New York : HarperCollins Publishers.

Barry, D,.\&Elmes, M. (1997). Strategy retold: Towards a narrative view of strategic discourse. Academy of Management Review, 22(2), 429-452

Birren, J. E., Kenyon, G., Ruth, J. E., Schroots, J. F., \&Svensson, T. (Eds.). (1996). Aging and biography: Explorations in adult development. New York : Springer Pub. Co.

Boje, D. (1991). The storytelling organization: A study of story performance in an officesupply firm. Administrative Science Quarterly, 36(1), 106-126.

Brendel, W. (2009).Exploring a framework for narrative driven transformations in medicine.Journal of Transformative Education,7(1), 26-43.

Butler, S. J., \& Bentley, R. (1997).Lifewriting: Learning through personal narrative. Scarborough, Ont.: Pippin Publishing.

Coogle.(2013). Coogle [Software]. Available from https://coggle.it/

Cordero, K., Nussbaum, M., Ibaseta, V., Otaíza, M. J., Gleisner, S., González, S., . . Carland, C. (2015). Read create share (RCS): A new digital tool for interactive reading and writing. Computers \& Education, 82, 486-496. doi:10.1016/ j.compedu.2014.12.006

Couldry, N. (2008). Mediatization or mediation? Alternative understandings of the emergent space of digital storytelling. New Media \& Society, 10(3), 373-391. doi: 10.1177/1461444808089414

Cinergix Pty. Ltd. (2013). Creately Online [Software]. Available from http://creately. com/

Dunford, R., \& Jones, D. (2000).Narrative in strategic change.Human Relations, 53(9), $1207-1226$.

DiMaggio, P. (1995). Comments on "What theory is not." Administrative Science Quarterly, 40(3), 391-397

Dupagne, M. (2010). Story circle: Digital storytelling around the world. Journal of Broadcasting \& Electronic Media, 54(3), 532-533. doi:10.1080/08838151.2010.498 704

Fisher-Yoshida, B., Geller, K. D., \& Schapiro, S. A. (2009). Innovations in transformative learning: Space, culture, \& the arts (Vol. 341). Peter Lang.

Horst, S. O., \&Järventie-Thesleff, R. (2016). Finding an emergent way through transformational change: a narrative approach to strategy. Journal of Media Business Studies, 13(1), 3-21.

Hrastinski, S. (2008). Asynchronous and synchronous E-learning. EDUCAUSE Quarterly, 31(4), 51-55

Hull, G. A., \& Katz, M. L. (2006).Crafting an agentive self: Case studies of digital storytelling. Research in the Teaching of English, 41(1), 43-81.

Kaufman, B. (2003). Stories that sell, stories that tell: Effective storytelling can strengthen an organization's bonds with all of its stakeholders. The Journal of Business Strategy, 24(2), 11-15.

Lambert, J. (2013). Digital storytelling: Capturing lives, creating community (4thed.). New York: Routledge.

Lazarus, R. S., \& Folkman, S. (1984). Stress, appraisal, and coping.New York: Springer Publishing Company. 
LeeTiernan, S., \&Grudin, J. (2001, July). Fostering engagement in asynchronous learning through collaborative multimedia annotation. In M. Hirose (Ed.), Proceedings of Interact 2001 (pp. 472479). Amsterdam ; Washington, DC: IOS Press.

Lodge, D. (1990). Narration is words. In H, Barlow. (Eds.) Images and understanding: Thoughts about images, ideas about understanding (pp. 141-153). Cambridge: Cambridge Uni Press.

Lucius-Hoene, G., \&Deppermann, A. (January 01, 2000). Narrative identity empiricized: A dialogical and positioning approach to autobiographical research interviews. Narrative Inquiry, 10(1), 199-222.

Markus, H., \&Nurius, P. (1986).Possible selves.American Psychologist, 41(9), 954969.

May, R. (1975). The courage to create. New York: W. W. Norton \& Company.

McClean, S. T. (2008). Digital storytelling: The narrative power of visual effects in film. Cambridge, MA: MIT Press

Mclntosh, D. N., Silver, R., \&Wortman, C. B. (1993). Religion's role in adjustment to a negative life event: Coping with the loss of a child. Journal of Personality and Social Psychology, 65, 812-821.

McKee, R. (June 2003) Storytelling that moves people.Harvard Business Review, 81(6), 51-55.

Merriam, S., \&Caffarella, R. S., (1999). Learning in adulthood: A comprehensive guide. San Francisco: Jossey-Bass. Free

Mezirow, J. (1978). Education for perspective transformation: Women's re-entry programs in community colleges. New York: Center for Adult Education, Teachers College, Columbia University.

Mezirow, J. (2000). Transformative dimensions of adult learning. San Fransisco, CA: Jossey-Bass.

Mezirow, J. \& Associates (2000). Learning as transformation: Critical perspectives on a theory in progress. The JosseyBass Higher and Adult Education Series. Jossey-Bass Publishers.

Nair, K. (1994). A higher standard of leadership: Lessons from the life of Gandhi. San Francisco, CA: BerrettKoehler.

Marshak, R.J. (1993). Managing the metaphors of change.Organizational Dynamics, 22(1), 44-56.

Oliver, G., \&Snowden, D. (2005).Patterns of narrative in organizational knowledge sharing.In G. Schreyögg\& J. Koch (Eds). Knowledge management and narratives: Organizational effectiveness through storytelling.Berlin: Erich Schmidt.

Padlet (2014).Padlet [Software]. Retrieved from http://padlet.com.

Palloff, R. M., \& Pratt K. (2007).Building online learning communities: Effective strategies for the virtual classroom. San Francisco, CA: Jossey Bass.

Park, C. L., \& Blumberg, C. J. (2002). Disclosing trauma through writing: Testing the meaning-making hypothesis. Cognitive Therapy and Research, 26(5), 597-616.

Park, C. L., \& Folkman, S. (1997). Meaning in the context of stress and coping. Review of General Psychology, 1(2), 115-144. doi: 10.1037/1089-2680.1.2.115

Pentland, B.T. (1999). Building process theory with narrative: From description to explanation. Academy of Management Review, 24(4), 711-724.

Phan, T., McNeil, S. G., \& Robin, B. R. (2016).Students' patterns of engagement and course performance in a massive open online course. Computers \& Education, 95, 36-44. doi:10.1016/ j.compedu.2015.11.015

Pratt, K. (1996). The electronic personality. Unpublished doctoral dissertation, Human and Organizational Systems Program, Fielding Institute 
Reason, P. \& Hawkins, P. (1988).Storytelling as inquiry.In P. Reason (Ed.).Human inquiry in action (pp.79-101). Newbury Park, CA: Sage.

Rossiter, M., \& Garcia (2010). Digital Storytelling: A New Player on the Narrative Field. New Directions for Adult and Continuing Education, 2010(126), 3748. DOI: $10.1002 /$ ace. 370

Sarıca, H. Ç., \&Usluel, Y. K. (2016).The effect of digital storytelling on visual memory and writing skills. Computers \& Education, 94, 298-309. doi:10.1016/ j.compedu.2015.11.016

Schein, E. (2004). Organizational culture and leadership.San Fransisco, CA: JosseyBass.

Shaw, G., Brown, R. \&Bromiley, P. (1998). Strategic stories: How $3 \mathrm{M}$ is re-writing business planning. Harvard Business Review, 76(3), 41-50.

Silver, R. L., Boon, C, \&Stones, M. H. (1983). Searching for meaning in misfortune: Making sense of incest.Journal of Social Issues, 39, 81-102.

Snowden, D. (2004). Narrative Patterns: The perils and possibilities of using story in organisations. In E. Lesser \& L. Prusak (Eds.), Creating value with knowledge (pp. 201-216). Oxford: Oxford University Press.

Strong, T., \& Psych, R. (2005).Relentless accountabilities and co-'authoring'our professional lives. Canadian Journal of Career Development, 4(2), 14-20.

Stormboard (2014).Online brainstorming and collaboration platform [Sofrware]. Retrieved from https://stormboard.com/

Taylor, E., \&Cranton, P. (2012). The handbook of transformative learning: Theory, research, and practice. Hoboken, NJ: John Wiley \& Sons

Varatek Software, Inc. (2012). MindApp [Software]. Available from http://www. mindapp.com/
Watson, T.J. (1995). Shaping the story: Rhetoric, persuasion and creative writing in organizational ethnography.Studies in Cultures, Organizations and Societies, 1, 301-11.

Weick, K.E. (1995) Sensemaking in organizations. Thousand Oaks, CA: Sage.

Williams, J., \& Hayler, M. (2016).Learning from stories of becoming.InProfessional learning through transitions and transformations (pp. 199-208).Springer International Publishing.

Wilson, A. L., \& Hayes, E.(2000). Handbook of adult and continuing education. San Francisco, CA: Jossey-Bass.

Yang, Y. C., \& Wu, W. I. (2012). Digital storytelling for enhancing student academic achievement, critical thinking, and learning motivation: A year-long experimental study. Computers \& Education, 59(2), 339-352. doi:10.1016/ j.compedu.2011.12.012

\section{Contact the Author}

\section{William Tate Brendel}

University of St. Thomas, Minnesota, USA Email:wbrendel@stthomas.edu

\section{Chientzu Candace Chou}

University of St. Thomas, Minnesota, USA

Email:ccchou@stthomas.edu 